Taylor, J. and Townsend, K. (2014) Reprogramming the Hand: Bridging the craft skills gap in 3D/digital fashion knitwear design, Craft Research, vol. 5 (2), pp. 1 October 2014.

\title{
Reprogramming the Hand: Bridging the craft skills gap in 3D/digital fashion knitwear design
}

\author{
Jane Taylor and Katherine Townsend, Nottingham Trent University, UK
}

\begin{abstract}
Designer-makers have integrated a wide range of digital media and tools into their practices, many taking ownership of a specific technology or application and learning how to use it for themselves, often drawing on their experiential knowledge of established practices to do so. To date, there has been little discussion on how digital knitting practice has evolved within this context, possibly due to the complexity of the software, limited access to industrial machinery and the fact that it seems divorced from the idea of 'craft'. Despite the machine manufacturers' efforts to make knitting technology and software more user-friendly, the digital interface remains a significant barrier to knitwear designer-makers, generally only accessed via experienced technicians. This article focuses on how this issue is being explored through practice-led research being undertaken by Jane Taylor at Nottingham Trent University. The investigation is a response to a skills gap between knitwear designers and the latest flatbed knitting technology and is grounded within the researcher's experience as both a knitwear designer and technologist. Through her practice,
\end{abstract}


Taylor explores how the Shima Seiki SDS1 CAD system can be used as a design tool, in order to use the SWG (3D Knit) machines more creatively. Specialist training has built on the researcher's tacit understanding of hand/machine knitting and pattern cutting, her established craft practice, where constant iterations can be made during the textile and shape creation stage. By reprogramming the hand, this research proposes a craft-based methodology that reverses the traditional relationship between making and technology, placing crafting at the centre of creative design practice where it can be applied to support and further the potential of advanced technology. This article is a revised version of a paper that was first presented by the authors at The First International Conference on Digital Fashion, at London College of Fashion in May 2013.'

\section{Keywords}

digital knitting technology

3D knitwear design

craft methodology

tacit knowledge

WHOLEGARMENT ®

seamless knitting

\section{Introduction}


This article discusses an aspect of a practice-based research project being undertaken by Ph.D. candidate Jane Taylor, at Nottingham Trent University, which is investigating the potential of integrating a craft-based approach to knitting using advanced 'whole garment' technology. The project is a response to a widely acknowledged 'skills gap' between knitwear designers and their ability to work directly with the latest flatbed knitting technology and is grounded within Taylor's past experience of being both a knitwear designer and knitwear technician. Taylor's design practice is influenced by the legacy of Japanese fashion design: the aesthetic possibilities attributed to garments both on and off the body, the beauty of the shadows created by a garment's contours and folds in 2D and 3D contexts, and particularly Issey Miyake's APOC 'a piece of cloth' (Frankel 2010: 63). The French costume designer Genevieve Sevin-Doering's principle of 'coupe en un seul morceau'/'cut from one piece of fabric' reinforces this concept, the aim being to create transformable garments, knitted as a single piece: 'allowing the final form of the garment to emerge in the hands of the wearer' (Fletcher and Grose 2012: 83). These key principals, which inform Taylor's ongoing, diagnostic practice, are being developed through research into traditional three-dimensional (3D) hand knitting alongside whole garment technology. The research synthesizes the use of draping on the stand and 3D CAD knitting technology by applying a craft methodology: working from the perspective of a 'designer' whose approach is different to that of a 'skilled technician'. It is generally accepted that a knitwear technician's knowledge is more in-depth than most knitwear designers, but that it is often naturally biased towards the training received from the machine manufacturer. So how can knitwear designers acquire the skills and knowledge required to engage creatively with digital knit technology? Harris suggests that practical 
advances in digital creation will not necessarily be achieved through simplification of software programs or the development of new software and hardware tools but rather through the encouragement of more users of the media (2012: 109). This project aims to highlight the added value that can be gained by the designer taking a more proactive approach to learning the technicalities of programming, working closely with the digital knit media, in order to explore the creative design potential of whole garment technology more comprehensively than is currently being evidenced.

\section{Background to the research}

The majority of seamless knitting is carried out on flatbed knitting technology and for the purpose of this project Taylor is concentrating on this area of knitting. Traditionally the most complex shapes produced on a flatbed knitting machine were the body or sleeve, and the shapes created were dependent on certain rules of knitting that limited the range of permutations. Although the technology has progressed, many of the traditional practices and skills have remained rooted in prior knowledge, and with the advent of whole garment knitting we often see the mimicking of existing classic garment shapes. Shima Seiki introduced their WHOLEGARMENT® knitting machine at the ITMA exposition in 1995, which was set to revolutionize the knitwear industry. After almost twenty years it is widely acknowledged that this complex technology is not being used to its full potential, chiefly due to the need for 'the role of the designers [to] change [and have] an ability to understand 3D design concepts and the machine parameters' (Sayer et al. 2006: 43). In the commercial fashion production environment for which this technology is built, the recreation of existing styles and garment shapes is often seen as a 
benchmark of the potential cost savings associated with it (Hurley 2013). To this end, a large automated database of standard garment shapes has been developed to assist in the complex programming process. Within a standard knitwear production model this database is hugely beneficial and reduces design development and sampling time; however this approach represents a barrier between the designer and the technology in terms of creative experimental engagement. These advancements, coupled with the disengagement from the craft of knitting, have led to a skills gap between knitwear designers and the technology.

According to Dormer, advanced technology is a product of 'distributed knowledge'; in this case the database represents a move towards the removal of risk-taking, which leads to the consistency and predictability of outcomes, for which the price is often uniformity (Dormer 1997a : 141). To truly understand the creative design potential of whole garment knitting technology, Taylor believes it would be beneficial for designers to develop an individual database of knitting techniques and garment shapes that would support the development of a range of processes that move beyond the generic approach of knitting tubes and connecting them at predetermined points on the garment. The creative potential of seamless technology is evident when looking at works such as 'Casablanca', a 3D, wearable sculpture, designed by Japanese Fashion designer Yoshiki Hishinuma. The designer worked with Shima Seiki to develop seamless pieces as part of his A/W 2005 collection. The garments blur the boundaries between art and fashion, having been shown in various exhibitions such as 'The Endless Garment', RMIT Gallery, Melbourne (2010), and 'Radical Lace and Subversive Knitting', New York (2007), both showcasing 
innovative relationships between surface/structural design and technology within knitted textiles.

\section{Overview of design and manufacture in the fashion knitwear industry}

Although very much depleted today, there remain a number of knitwear manufacturers in the United Kingdom in which design and manufacture are practiced under the same roof. It may often be the case that the company produces knitwear for customers who also have in-house designers. In this case the designer based at the manufacturers will interpret the customers' ideas and work with the technician to achieve them. In the United Kingdom there are only a handful of knitwear manufacturers producing their own brand, for example John Smedley, Lea Mills, Derbyshire, and Lyle \& Scott, Selkirk, Scotland, both offering very traditional stitch patterns and silhouettes. A more common model within the industry today is the design being carried out in one location and the manufacture in another. As shown in the diagram below, design can be produced through an in-house design studio working specifically for a brand, such as Alfred Dunhill, London, or through a freelance designer or swatch agency who could be working for several brands; in both cases the knitwear design process is essentially linear, the designer produces the aesthetic design and passes it to the technician who, in turn, interprets it into a garment.

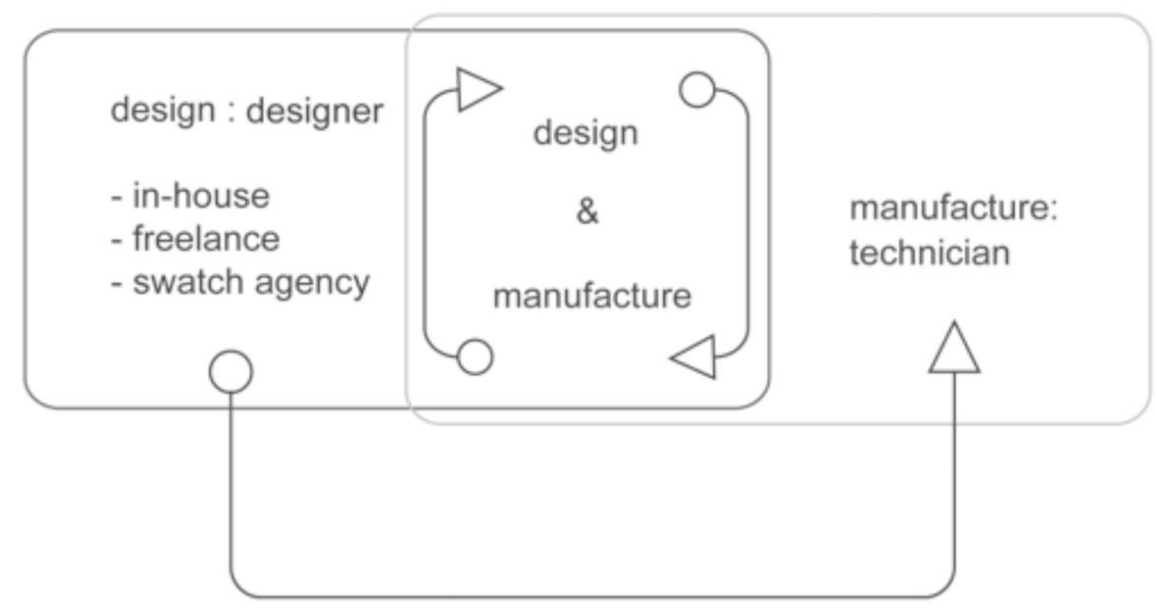


Figure 1: Jane Taylor 2013: Overview of design and manufacturing models in the knitwear industry (C) Taylor.

Eckert's study of the communication issues between knitwear designers and technicians highlighted a lack of teamwork, concluding that the poor communication was down to 'differences in cognitive styles and backgrounds' (2001). However, in her literature on managing creativity, Amabile suggests that a design team should have a diversity of perspectives and backgrounds that are mutually supportive (1998). According to Eckert (2001) and Taylor what often seems to be lacking is the understanding that each member of a team should recognize [and respect] the unique knowledge and perspective brought to the table by the others. In Eckert's (2001) study she found that technicians' opinions of designers and vice versa were often negative, only recognizing what they considered to be shortcomings, with many technicians complaining that designers lacked technical knowledge and designers suggesting technicians were reluctant to try new ideas. Taylor proposes that if such a team were managed differently and they worked collaboratively together 'as a team', then the linear design process could be replaced by something that reflected and responded to the iterative nature of design more holistically.

\section{Retaining control}

When training as a knitwear designer in higher education, one has considerable autonomy over the process, as one is most likely to be working independently, often to an individual brief on hand-flat machinery to develop samples including complete garments; indeed some haute couture knitwear designers still work in this way. Mark Fast and Derek 
Lawlor are two contemporary knitwear designers creating innovative garments that 'push the boundaries between art and fashion' (Loomes 2010). Both sample their ideas on domestic knitting machines. Fast goes as far as manufacturing his haute couture range on domestic machinery using outworkers. In an interview, he said that the reason he loved knitwear design was that he's '[-] in control of the dynamic qualities which can be produced by the machine' (Heran 2011). Fast maintains autonomy over the process by working without the need for a technician, he can rely on his own expertise and therefore is free to experiment and take risks in his designing. In contrast to this, Taylor proposes that knitwear designers in the commercial fashion industry have relinquished control over this important part of their practice, the realization and success of their ideas often being dependent on the attitude and skill of the technician. The linear nature of the design process is such that the key communication act is the handing over of design specifications to a different team member [a technician] in many cases located in a different country (Eckert 2001). In an interview with a designer based at a UK knitting manufacturers, they described how designers communicated with the technicians through a middleman, despite being based in the same office (Thomas 2012). This separation of the aesthetic and technical aspects of knitwear design, when the two are so interdependent, seems perverse but is not unusual in the fashion and textile industry. This estrangement brings us back to the issue of skills acquisition and the importance to craftbased designers, like Fast, of 'retaining control at the point of production' (Frayling 2011 in Shercliffe 2012: 164). As Shercliffe states:

Although he [Frayling] was referring to criticism of nineteenth-century ideals 
of craftsmanship, his concept of the significance of retaining control in production, and the consequent contribution to innovative products and business models, is just as relevant today. (2012)

In contrast with Fast's outworker approach, which avoids the use of digital knitting technology, Taylor's model of practice seeks to synthesize traditional, aesthetic qualities with technically advanced processes. The model builds on Martin Woolley and Rob Huddleston's concept of 'crafted control', which proposes closer collaboration between designers and engineers within advanced automated textile production, and where 'craft intervention' can contribute to the development of smart tools and materials (Shercliffe 2012: 167). Knitwear designer and researcher Sooyung Yang has gone a step further by adopting the position of 'designer interpreter' for which she carries out the roles of designer, technician and machine operator. She has set up the Fashion Hub, an alternative design and manufacturing model for developing high-end knitwear, based at Curtin University in Perth, Australia. The Fashion Hub offers a design consultancy for designers to develop samples on a Shima Seiki SES 183S• WHOLEGARMENT® knitting machine. ${ }^{2}$ Yang's background is in design, having worked as a high-end fashion designer in South Korea, and later undertaking a Ph.D. research project for which she learnt how to program and run the seamless garment knitting machine. Her experience, skills and knowledge have placed her in an ideal position to bridge the gap between designers and whole garment technology, whilst achieving autonomy over the digital design process as a designer in her own right. 


\section{Developing a craft methodology}

It is difficult to identify a specific craft methodology for fashion knitwear design for practitioners who combine both the aesthetic and technical aspects of design; however researchers in the field have touched on it. For example, Shaw developed the idea of 'crafting the technological' as a methodology, working with a technician to produce seamless 'base units' using Shima Seiki WG technology, but having very little connection with the process. She describes how she re-established an emotional connection to the garments through hand and craft processes used for the "postproduction customization' of the garments (Shaw 2009: 59). Yang, Smith and Underwood all took on the role of technical designer with a view to working creatively with seamless technology and engaging with programming. Although none developed a specific craft methodology, Yang suggested the deliberate use of 'trial and error' as a means of 'extending the high fashion performance envelope of seamless technology through unexpected solutions (2010: 155)'; and both Smith (2013) and Underwood acknowledged that ' $3 \mathrm{D}$ shape knitting has the potential to engage in expanding ideas to do with [-] the reconsideration of craft in a digital context (Underwood 2009: 154)' as possibilities for future directions in knit. In response to this, my research asks what would be the implications of a knitwear designer having greater control over the programming and knitting of seamless garments, and taking a craft approach to digital knitting technology.

From Ruskin's ‘tendency to suggest ways forwards by looking backwards' (Adamson 2010: 139) to McCullough's (1998) forward thinking Practiced Digital Hand, the status 
and definition of 'craft' has been an ongoing debate, the main bone of contention being around the use of technology (any machinery) versus the use of the hand. Both Pye ([1968] 1995) and Dormer (1997b) acknowledge that technology and craft exist side by side and are interdependent within certain practices. Most craftspeople have historically used tools (technology), but what has changed is the extent to which people are in control of those tools.

During the last ten years, the emergence of more accessible digital tools have beguiled and challenged a genre of maker, which has ignited debate around the topic of craft and computing. (Harris 2012: 92)

For example, a knitwear designer may work on knitting pins, manual knitting machines or domestic electronic machines, where each places the user, to varying degrees, in control of the process, which the authors argue can be described as a form of craft. To adopt one definition offered by Dormer, 'craft means a process over which a person has detailed control, control that is the consequence of craft knowledge' (1997b: 7). In contrast, a knitwear designer working in the industry today now rarely interacts with the process of knitting, only that of designing. The aesthetic and technical elements of the craft of knitting have been pragmatically separated into two distinct roles, designer and technician. If a designer has been trained specifically in knitwear design they will be able to draw on their experiences and craft knowledge, but as they rarely engage directly with the machinery they can no longer be described as a craftsperson. To use Pye's ([1968] 1995: 20) terminology, they are no longer engaging in the 'workmanship of risk' but 
rather the 'workmanship of certainty', whereby both designer and technician have a shared responsibility to produce garments efficiently, cost-effectively and that are fit for purpose, resulting in limited opportunities or time for experimentation. As with most digital technologies, knitting machinery was developed to produce products similar to those already in existence more efficiently, expediently and to a standard quality that could be predetermined. Initially, the machinery mimicked what was already possible to produce by hand and therefore knitwear designers could draw on their tacit knowledge or produce initial samples on hand-flat machinery that could be translated for industrial production. However, as the technology has advanced, the possibilities have outgrown what can be achieved on hand-flat machinery and therefore the extent of most designers' craft knowledge. Seamless technology recreates the craft of seamless knitting in its earliest form, produced by hand, on a variable number of pins - the technology used by the original knitwear industry in the United Kingdom. Taylor suggests that designers who are skilled in hand knitting in the round will be able to apply their tacit knowledge when designing for industrial whole garment machinery, and has revisited this traditional hand skill as part of her research practice.

Drummond Masterson, a maker engaged with digital technology, strives to know his tools in the same way as any other craftsperson, forming an in-depth understanding of the software. He is wary that the standardized tool sets embedded within software, the 'distributed knowledge' (Dormer 1997a : 139), can undermine the autonomy of the maker and lead to uniformity (Masterson 2007; Dormer 1997a), and therefore he takes time to master the software so that he can take on an exploratory approach to the process. 
The complexity of the software for seamless garments has necessitated a rationalization of the process of programming, in the form of a database of predetermined garment shapes. ${ }^{3}$ In order to create viable, seamless garments cost-effectively in the knitwear industry today, skilled technicians (programmers) can become merely information processors carrying out 'goal-directed, plan-controlled action' (Wright and McCarthy 2004: 30). The software is such that it is possible to engage with it on many different levels depending on the skills of the programmer and the context in which they are working. It can be used as an 'information-processing model', using the 'workmanship of certainty' (Pye [1968] 1995), choosing a garment from the database and allowing the software to do all the work. However, there is also the possibility to take a 'practice' approach and build programs from scratch, to create individual digital artefacts that embody the experience and knowledge of the user. For this research Taylor is adopting a practice approach to the technology, treating the programming as a new form of digital craft, drawing on her existing knowledge, both explicit and tacit. Yang (2010) took on the role of 'Designer Interpreter', and similarly, Taylor re-amalgamated the technical and design elements of knitwear into a single role as a 'Technical Designer'. In this way, she is able to demonstrate what Adamson refers to as 'digitalize', through the creation of whole garments that also reflect her individual sensibilities and handwork skills as a maker (Adamson 2010 in Harris 2012: 92).

\section{Knowledge and skills acquisition}

Taylor's experience to date includes both industrial and craft-based knitting: her experience of working with the latest technology in industry in the early 1990s provided 
insights into what was possible in terms of creative design. An interest in developing garments with minimal processes post knitting was carried through into her role as knitwear tutor at the University of the West of England, where she explored this concept without the constraints of industry and with the freedom of working on hand-flat knitting machines; therefore, both her work and that of the students was experimental and craft based. The undertaking of a Masters degree at Nottingham Trent University provided the opportunity to engage again with industrial machinery using the 'workmanship of risk' not 'certainty' as was the case when she was first working in the knitwear industry. She endeavoured to maintain control over the process by learning how to program and run the industrial machinery. Her current research has developed those skills further to work with whole garment technology in the form of Shima Seiki SWG accessory machines. ${ }^{4}$ Despite being an expert in hand-flat machine knitting, the physical process of producing a knitted fabric using an industrial machine requires a completely new knowledge base. The technology is complex, but there are many similarities as well as differences between hand-flat and industrial machinery. Taylor's embodied knowledge of hand knitting and hand-flat knitting machinery ${ }^{5}$ has enabled her to make the leap to advanced technology, in order to engage with it and control it from a creative viewpoint. There is no doubt that when moving from using hand techniques to digital production and manipulation, one loses touch with the materiality of the process, the majority of the work being done through a computer interface.

[However]...there is some possibility of craft in the electronic realm. Visual thinking, tacit knowledge of tools, experience in the affordances of media, 
and intelligent practices all may yet combine to make these devices worthwhile. (McCullough 1998: 271)

Although digital tools have become more accessible and workable, it is still natural for makers, trained in a pre-CAD age, to revisit traditional 'hand, eye, material' approaches as a way-in to digital fabrication (Harris 2012: 93). Taylor found it particularly useful to return to hand-flat machinery and re-conceptualize the hands-on process in terms of an industrial knitting machine. In common with many practice-led researchers before her, she discovered that the digital process was not a total solution or an end in itself and that it could be influenced by knowledge of the hand-knitting discipline and vice versa. For example, by taking up seamless hand knitting using pins (needles), she gained more of an understanding of how the industrial machines create a 3D garment. And in turn, the knowledge gained through programming and working with the technicians informed the methods used to create shaping by hand. Working in this iterative way allows more freedom to experiment, take risks and develop a new design methodology, which combines 'both hand and machine processes [and] draws on [...] embodied knowledge at the same time as taking advantage of disembodied technologies (Philpott 2012: 67). This approach underpins the importance of 'craft intervention' (Woolley and Huddleston in Shercliffe 2012: 167) in the digital realm and raises parallels with McCulloch's (1998) notion of 'the practiced digital hand', whereby the hand's tacit knowledge of physically knitting in the round subsequently informs the way the digital knitting machine is programmed. This represents a 'reprogramming of the hand' to perform a new task, but 
one that will result in a (more) craft-oriented product that reflects the designer's specialist, experiential knowledge.

Dormer suggests that not all crafts can be learnt through trial and error, and gives classical dance as one example, explaining that classical dance is a language that can only be learnt by mimicking experts. He describes such crafts as 'disciplines' (1997c: 220). With this in mind, Taylor proposes that the programming of industrial knitting machines is also a discipline, which needs to be taught, not only because of its complexity but also the potential costly damage that could result from allowing a novice to freely experiment with the technology. The training for technicians on advanced knitting technology is, therefore, often based on the rigid instruction delivered by the machine builders; the complexity of the software is such that the instruction is non-negotiable and based on the principle of there being a right and a wrong way of doing something. As Dormer (1997c: 220) suggests, this type of learning does not always encourage creativity. The programming knowledge is no longer rooted in a how-to knowledge of knitting but a distributed knowledge of negotiating the software. As discussed, Taylor was trained to work on manual tools such as knitting pins and machines, and thus her design skills are underpinned by a tacit knowledge of how to produce knitted fabrics and construct knitted garments. This 'know-how' (Dormer 1997a: 139) embodies knowledge of materials, processes and structures, and through the role of designer-maker these can be explored spontaneously allowing for improvisation and experimentation. These differences in knowledge acquisition impact greatly on the way designers and technicians approach the 
programming of (Shima Seiki) knitting software, and have implications for other disciplines reliant on sophisticated computerized applications.

There is a difference in the culture of the knitwear design studio and knitwear manufacturer; therefore friction can occur between the designer and the technician when the latter is training the former. Yang identified the need for machine manufacturers training to improve, in order to help bridge the gap between the professional cultures and practices of fashion designers and the more technical culture of those providing the teaching (2010: 212). Having undertaken formal training at Shima Seiki headquarters in Japan, Taylor suggests that the programs offered are being tailored more towards the individual or specific requirements of a company. However, there is still an expectation that designers will concentrate on the design side of the software, which focuses on visualizations of design ideas as opposed to the programming of new garments. Taylor received one-to-one training, tailored around her specific needs, which were to program outside of the database of predetermined garment shapes. The quality of the training was excellent; however with hindsight it is clear that there was an underlying aim to

encourage her to work with the 'distributed knowledge', as she was constantly steered towards using the database of predetermined shapes.

\section{The craft practice of 3D digital knitting}

Seamless knitting is a recognized form of zero waste design, the aim being for the garment to emerge from the machine with as little making-up or wasted fabric as possible. As knitwear naturally encompasses stretch, there is natural 'ease' built into the 
garment; but depending on the yarn and stitch structure this can be limited, and therefore the design still relies upon expertise in pattern cutting and construction techniques. Working with 3D digital knitting, to develop transformable garments has required Taylor to rethink her approach, or as zero waste designer Mark Liu has said, 'unlearn' everything she knew about pattern and garment design (Liu quoted in Townsend and Mills 2013: 107).

The impression is often given that there is a specific or correct approach, which makes every practitioner a beginner and yet a pattern cutter's background, the application of their ideas and experience can give life to many new ways of working. Each practitioner must find their own method of working within zero-waste, how to start from a different angle, using alternative methods to the basic block, which creative cutters can relate more instinctively to. (Townsend and Mills 2013: 109)

As Taylor does not wish to work from the existing databases, instead taking a practice approach, the development of her research was dependent on her ability to learn how to program using PAC data. PAC data are simply a means of condensing complex knit code into a simple but 'readable' graphical colour representation of the stitch/garment structure. This enables the programmer to easily manipulate the shape and structure of the design prior to de-packing, ${ }^{6}$ which will then insert the complex knit code to create the program. This combined understanding and application of craft and technology 'can lead to garments that surpass those created by conventional methodologies', through 
integrating the computer as a primary tool, supported by the knowledge of craft skills and the inherent properties of knitwear (Harris and Braddock-Clarke 2012: 188).

The PAC data and the compressed file are integrated through the automatic processes built into the software, and developed to produce the knit code (the programme) required to control the knitting machine.
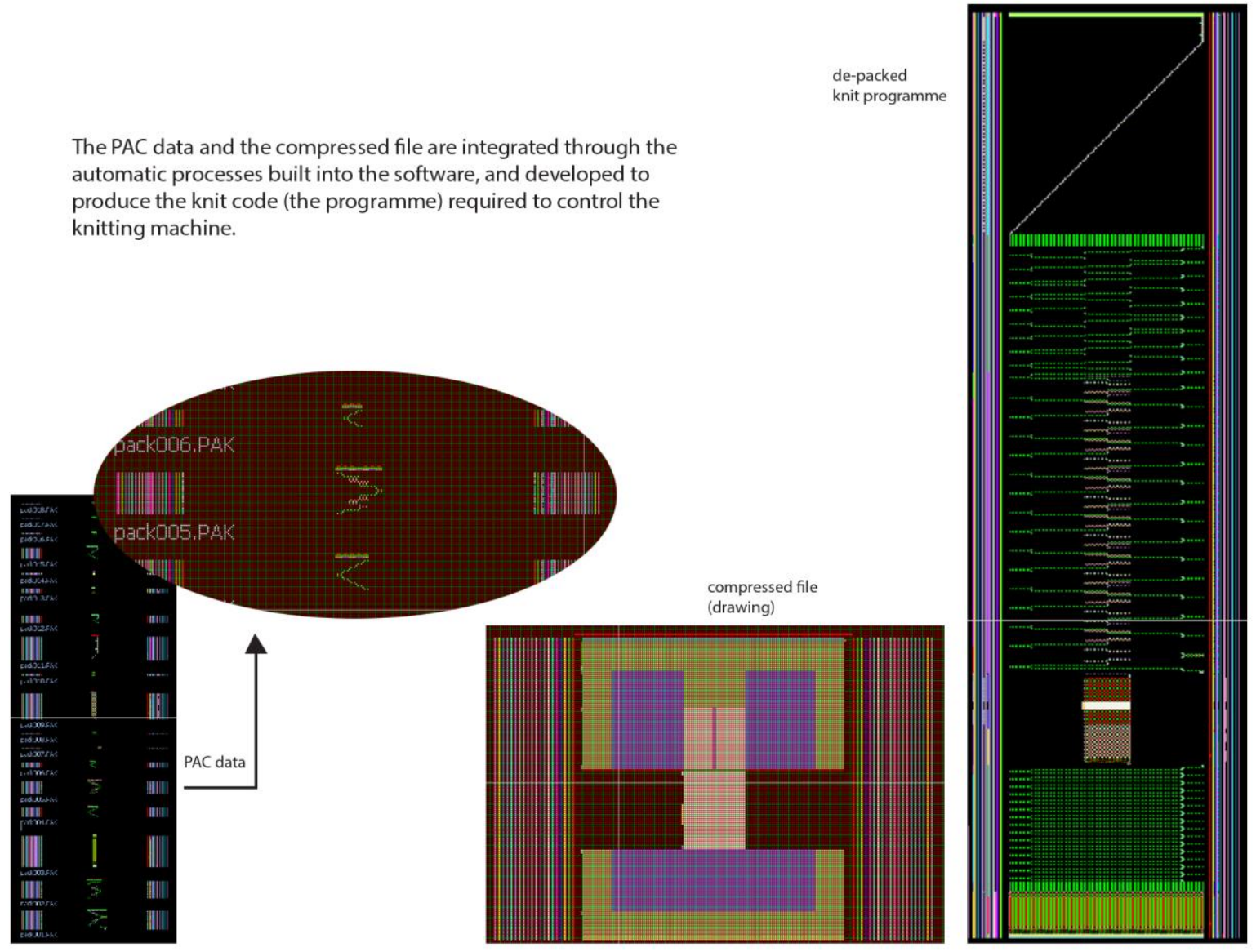

Figure 2: Jane Taylor (2014) Development of PAC data and the compressed drawing to create a knit programme. () Taylor.

Taylor's method challenges the traditional use of advanced knitting technology by approaching it from an experimental design perspective, working with the Shima Seiki SWG WHOLEGARMENT® as a starting point, or design tool, as opposed to a prescribed menu of available shaping strategies. In contrast with most commercial 
fashion design, this approach starts with a process rather that a sketch, or garment specification. The first stage is draping, or modelling on the stand, which is a relatively free, intuitive process with few restrictions; however when returning to the knitting machine, the designer must be able to program the new developments in order to realize a sample that relates to the toile. In this context, the initial complexity of programming is a constant barrier between ideas and knitted samples, but one that is important to break down in order to understand the possibilities. As with any process, it is often the doing and the making of mistakes that can lead to innovative developments. The idea of being hands-on with the software and using it with hand/digitalize as part of the overall tool kit, as opposed to a perfectly produced end in itself, is the key focus of the project and echoes the work of craft research from other areas of practice.

The skilled and sensitive human interaction with technology that is involved in poetic object making is arguably central to the maker's art. A direct relationship with tools enables the maker to engage intimately with materials and process to create finished objects with a high degree of autonomy and control over quality. (Bunnell 2004: 2)

The tube of fabric is a central concept to the development of seamless knitting, with multiple tubes connecting at specific points such as the underarm. In its simplest form, a seamless garment consists of three tubes: sleeve, lower body and sleeve, and is knitted from the bottom up. All three tubes are produced simultaneously on the knitting machines 
up to the underarm, at which point they are connected together to form one tube (upper body).

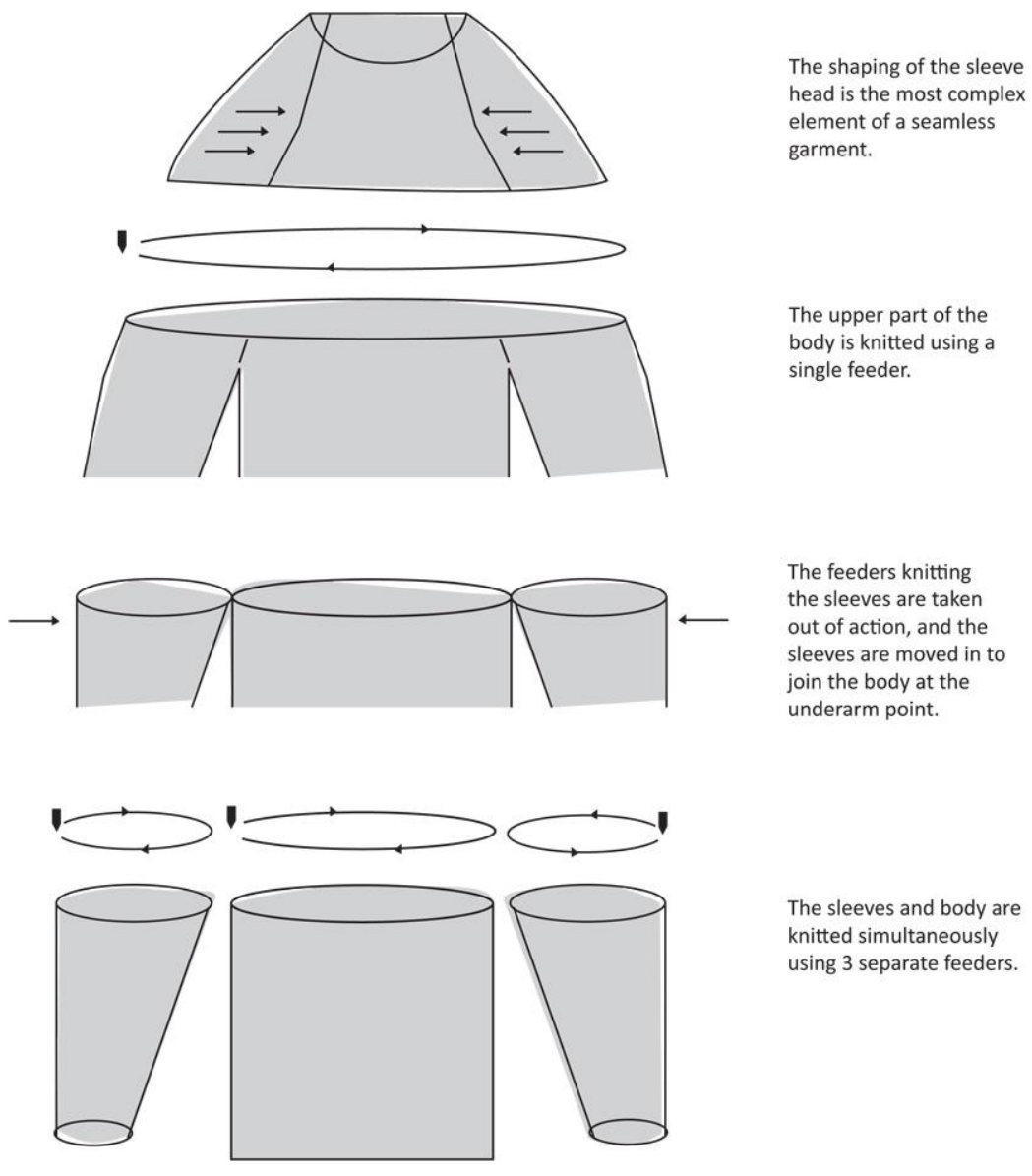

Figure 3: Taylor (2014) The basic construction of a seamless garment, the 'bottom up' approach. () Taylor.

Whilst these tubes are critical for the development of seamless knitwear, Taylor believes that this bottom-up knitting approach, which mimics existing garment shapes, does not take full advantage of the range of complex shapes that are possible. She has identified the point at which the sleeve joins the main body of the garment, as being the most 
complex area to program and the reason why predetermined programs are necessary. Therefore, traditional styles such as the saddle shoulder and the set-in sleeve are difficult to modify and adapt for fit and style, which is one explanation for a lack of diversity in the design of seamless garments. Taylor has focused on this design aspect in her research practice and, by avoiding using the traditional seamless methods, has created a new sleeve silhouette, shown in Figure 4. The three dimensionality of the sleeve is formed from a concertina effect of three layers of fabric that lay flat when off the body but open up when worn. The fit obviously differs from that of traditional sleeve styles and can be easily modified through scale, forearm shaping, position of 'sleeve head' and method used to shape the shoulder to produce many variations.
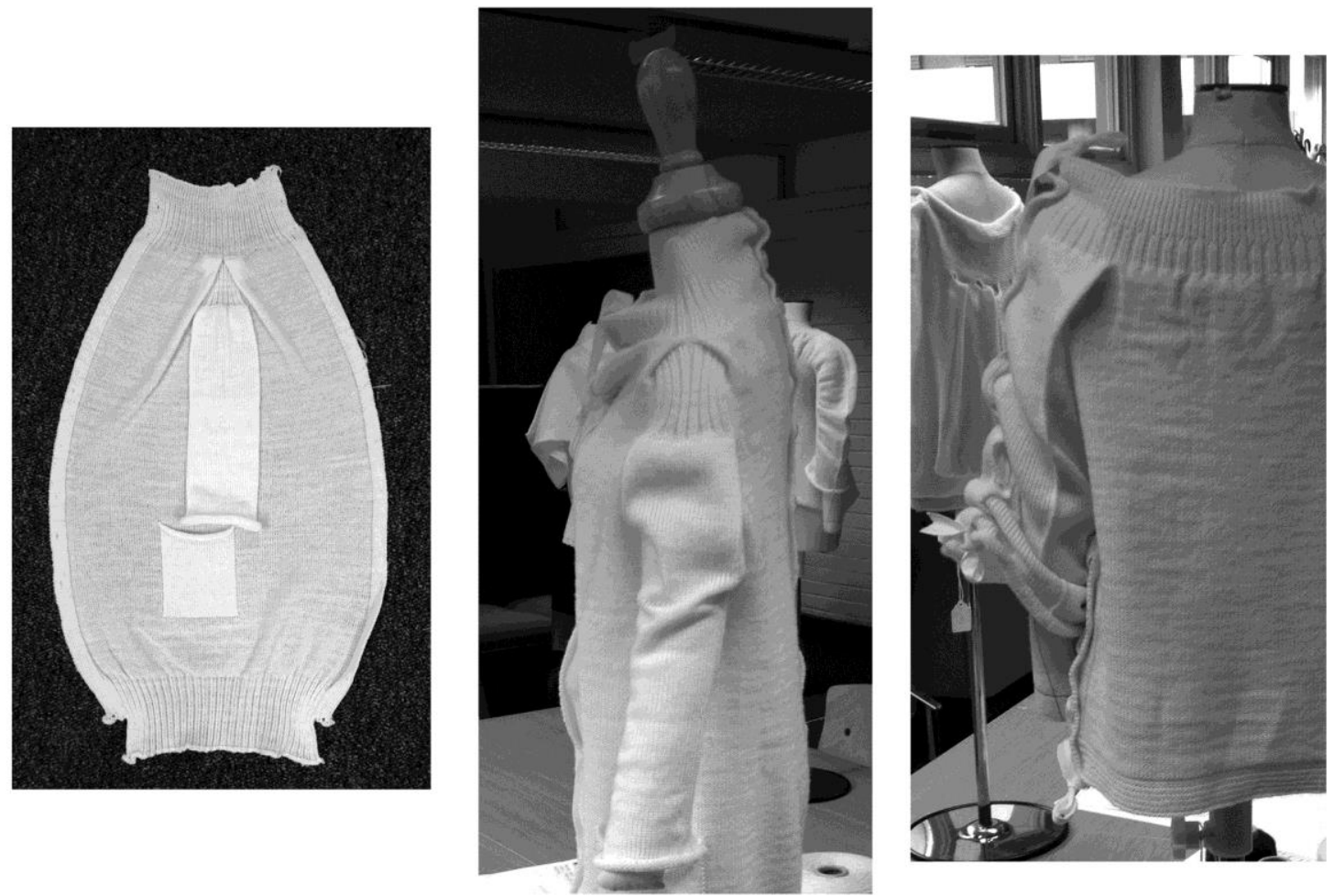

Figure 4: Taylor (2014) The pleat sleeve. (C) Taylor. 
Taylor has used the software to craft her ideas into knit programs, avoiding existing preprogrammed data but relying on many of the inbuilt automatic 'toolsets' that make it possible to work with the easily recognizable graphic icons. By working in this way she undertakes the 'workmanship of risk' in her practice albeit heavily regulated, as opposed to those who work mostly with the predetermined PAC data and thus take minimal risk and can be more assured of the outcomes.

\section{Conclusion}

Seamless knitting technology is at the centre of this research project and continues to be developed for more widespread commercial use. However, designers in the knitwear industry have had little opportunity to engage with learning the technical aspects of programming the machines, as even those designers based in companies with in-house manufacturing rely on the knowledge of technicians to realize their ideas. Whole garment digital knitting machinery has been developed to produce garments based on existing pattern shapes more efficiently in the spirit of the 'workmanship of certainty', which does not allow for opportunities to experiment and innovate. Therefore, the full potential of seamless technology is still not being evidenced in high-fashion knitwear, and it is only when designers have the rare opportunity to collaborate closely with skilled knit technicians that we catch glimpses of what is possible.

This research project demonstrates that in order to develop new shaping strategies and outcomes it is important that designer/researchers more fully utilize access to training and technical expertise in order to be able to take their own creative risks and experiment. 
Applying programming skills alongside existing knowledge of garment modelling and knitting to create $3 \mathrm{D}$ sketches and prototypes, it is possible to formulate innovate designs that challenge the constraints and pressures of the knitwear industry. By designing between 2D and 3D contexts in an iterative manner, the digital knitting process is both interrupted and informed, resulting in the development of a unique craft-based methodology. Within this methodology, it is envisaged that the programming will become a more integral and intuitive part of the process. This approach builds on the idea of 'craft intervention and control' enabling the designer/researcher to be more involved at the 'point of production', leading to greater autonomy over the more unfamiliar aspects of the design process, leading to more creative use of the Shima Seiki SWG machine as a design tool.

There has been considerable focus on the practical advantages of computerized design and manufacture, formerly known as CAD/CAM. We are now at a point in the development of advanced technological production where the combining of embodied, tacit knowledge and skills in all making disciplines are being reassessed and reincorporated into the process of digital creation. The research methodology outlined in this article provides a solution for bridging the 'skills gap' in seamless knitting, which could be reversed if the role of the designer was reimagined and redefined. More design practitioners need to be encouraged to experiment by engaging with the technology and through creative collaboration with technicians. Insights from this Ph.D. research will contribute to understanding what the new role of the designer might constitute, and how a 
new dynamic between the technical and aesthetic aspects of knitwear design could lead to innovation and contribute towards the development of new manufacturing models based on the possibilities of future fabrication.

\section{References}

Adamson, G. (2010), Thinking Through Craft, Oxford, UK: Berg, in Association with V \& A Publications.

Amabile, T.M. (1998), 'How to Kill Creativity', Harvard Business Review, September-

October. http://www.sagepub.com/upm-data/11444_02_Henry_Ch02.pdf

Accessed 10 January 2013

Bunnell, K. (2004), 'Craft and digital technology', World Crafts Council 40th

Anniversary Conference, Metsovo, Greece, 31 May - 2 June 2004.

http://www.autonomatic.org.uk/team/kb/craft\%20and\%20digital\%20technology.pdf.

Accessed 23 January 2013.

Dormer, P. (1997a), 'Craft and the Turing Test for practical thinking', in P. Dormer (ed.),

The Culture of Craft, Manchester and New York: Manchester University Press, pp. 137-

57.

(1997b), 'The Salon de Refuse?', in P. Dormer (ed.), The Culture of Craft, Manchester and New York: Manchester University Press, pp. 2-16.

(1997c), 'The language and practical philosophy of craft', in P. Dormer (ed.), The 
Culture of Craft, Manchester and New York: Manchester University Press, pp. 219-30.

ECKERT, C. (2001) 'The communication Bottleneck in Knitwear Design: Analysis and Computing solutions', Computer supported co-operative work 10. [online] Kluwer Academic Publishers, Netherlands. Pp. 29-74. Available at: http://www.cse.dmu.ac.uk/ mstacey/pubs/bottleneck/fulltext.pdf Accessed 04 June 2013

Eckert, C. and Stacey, M. (1994), 'CAD Systems and the Division of Labour in Knitwear Design', in A. Adam, J. Emms, E. Green and J. Owen (ed.), Women Work and Computerization: Breaking Old Boundaries-Building New Forms, Amsterdam, The Netherlands: North-Holland, pp. 409-22.

Fletcher, K and Grose, L. (2012), Fashion \& Sustainability, Design for Change, London: Laurence King publishers Ltd.

Frankel, S. (2010), 'Flatness', in C. Ince (ed.), Future Beauty: 30 Years of Japanese Fashion, London: Merrell Publishers Ltd., pp. 63-83

Frayling, C. (2011), On Craftsmanship, London: Oberon Books.

Harris, J. (2012), 'Digital practice in material hands: How craft and computing practices are advancing digital aesthetic and conceptual methods', Craft Research 3:1, pp. 91-112.

Harris, J. and Braddock-Clarke, S. E. (2012), Digital Visions for Fashion \& Textiles: 
Made in Code, London: Thames \& Hudson

Heran, F. (2011), 'The knitwear interview - Mark Fast, Derek Lawlor, cooperative designs and Ramon Gurillo', Fashion 156, 19 March, http://archive.fashion156.com/blog/The\%20Knitwear\%20Interview\%20\%20Mark\%20Fa st,\%20Derek\%20Lawlor,\%20Cooperative\%20Designs\%20and\%20Ramon\%20Gurillo/32 39/. Accessed 23 January 2013.

Hurley, W. (2013), Personal interview, 16 October, Nottingham Trent University.

Loomes, V. (2010), 'Craig Lawrence interview', Fashion 156, http://archive.fashion156.com/feature.php?p=309\&issue=14. Accessed 23 January 2013.

Masterson, D. (2007), 'Deconstructing the digital', New Craft-Future Voices, Conference Proceedings, Dundee : Duncan of Jordanstone College of Art and Design, pp. 7-24.

McCarthy, J., Wright, P. (2004), Technology as Experience, Cambridge, MA and London: The MIT Press.

McCullough, M. (1998), Abstracting Craft-The Practiced Digital Hand, Cambridge, MA and London: The MIT Press.

Press, M. (2007), 'Handmade Futures: The emerging role of craft knowledge in our digital culture', in S. Alfoldy (ed.), Neo Craft: Modernity and the Crafts, Nova Scotia, Canada: the press of the N.S.C.A.D, pp. 249-66. 
Pye, D. ([1968]1995), The Nature and Art of Workmanship, London: The Herbert Press.

Sayer, K., Wilson, J. and Challis, S. (2006), 'Seamless Knitwear: The design skills gap', The Design Journal, 9:2, pp. 38-51.

Shaw, A. (2009), 'Crafting the Technological: Ganseys and WHOLEGARMENT® Knitting', Ph.D. thesis, UK: Manchester Metropolitan University.

Shercliffe, E. (2012), 'Review of textile research in process: An international symposium exploring the role and relevance of traditional hand skills in contemporary textiles, and the value and status of craft process. School of the Arts, Loughborough University. UK, 16-17 November 2011', Craft Research 3:1, pp. 164-71.

Smith, A. (2013), ‘Seamless knitwear: Singularities in design', Ph.D. thesis, New Zealand: Auckland University.

Thomas, N. (2012), Personal interview, 22 October, London.

Townsend, K. and Mills, F. (2013), 'Mastering Zero: How the pursuit of less waste leads to more creative pattern cutting', International Journal of Fashion Design, Technology \& Education, 6:2, pp. 104-11. 
Underwood, J. (2009), 'The design of 3D shape knitted preforms', Ph.D. thesis, Melbourne Australia: RMIT University.

Yang, S. (2010), 'A creative journey developing an integrated, high-fashion knitwear development process using computerized, seamless v-bed knitting systems', Ph.D. thesis, Perth, Australia: Curtin University of Technology.

\section{Contributor details}

Jane Taylor is a designer maker, an academic researcher and an educator within the field of knitwear design. After working as a knitwear designer in industry for several years she embarked on a teaching career that took her to UWE in Bristol, where she worked as a technical instructor in knit for ten years. In 2010 Jane returned to studying, and undertook a Masters in fashion knitwear design at Nottingham Trent University, graduating with distinction in 2011. She is currently engaged in her doctoral research, entitled 'The Technical Designer: A new approach for creating seamless knitwear', due for completion autumn 2015.

Dr Katherine Townsend is Reader in Fashion and Textile Crafts in the school of Art and Design at Nottingham Trent University. She leads the Digital Craft and Embodied Knowledge research group as well as the M.A. Applied Design Futures courses encompassing M.A. Fashion, Knitwear, Textile Design Innovation and Contemporary Craft Practice. She originally trained and worked as a designer maker in the fashion and 
textile industry. She was awarded a doctorate in 2003 for her practice-led Ph.D., 'Transforming Shape', which investigated the integration of fashion and textile design using traditional and digital technologies. Her postdoctoral research is focused on the potential materiality of digital crafting approaches how the synthesis of disparate technologies and approaches can lead to innovation. Katherine has presented lectures, published papers, curated exhibitions and exhibited her research outcomes internationally.

\section{Contact:}

Fashion, Knitwear \& Textiles, School of Art \& Design, Nottingham Trent University, Burton Street, Nottingham, NG1 4BU, UK.

E-mail: Jane.taylor2011@my.ntu.ac.uk

Email: Katherine.townsend@ntu.ac.uk

Notes

${ }^{1}$ Digital Fashion 2013 was an inaugural event organized and hosted by Fashion Digital Studio, London College of Fashion, University of the Arts London, 16-17 May, which established a premier international forum for the dissemination of novel scholarly work 
on the interplay between fashion, digital technology and interaction design. See http://digitalfashionconference.com.

${ }^{2}$ Shima Seiki SES $183 S \cdot$ WHOLEGARMENT® is capable of knitting complete garments and is an extremely flexible machine with the capability to perform fine-gauge shaping and integral knitting.

${ }^{3}$ A standard toolset found in the Shima Seiki WHOLEGARMENT and Stoll Knit and Wear software.

${ }^{4}$ Shima Seiki SWG-N is a compact WHOLEGARMENT ® knitting machine for producing seamless gloves, socks, hats and leggings.

${ }^{5}$ Semi-automated, mechanical knitting machines powered manually. The 'risk' is regulated by built-in automatic features, but the user requires a high level of skill and dexterity to operate the machine.

${ }^{6}$ De-packing is the process of combining groups of PAC data with a compressed drawing using the automatic toolsets embedded in the software, to create a programme that can be used to control the knitting machine. 